\title{
Leading dietary determinants identified using machine learning techniques and a healthy diet score for changes in cardiometabolic risk factors in children: a longitudinal analysis
}

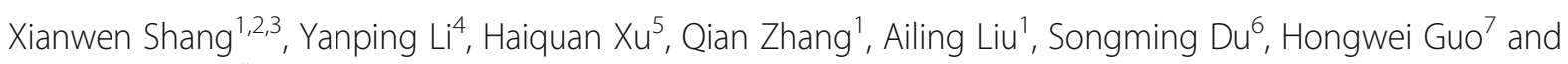
Guansheng $\mathrm{Ma}^{8^{*}}$ (i)

\begin{abstract}
Background: Identifying leading dietary determinants for cardiometabolic risk (CMR) factors is urgent for prioritizing interventions in children. We aimed to identify leading dietary determinants for the change in CMR and create a healthy diet score (HDS) to predict CMR in children.

Methods: We included 5676 children aged 6-13 years in the final analysis with physical examinations, blood tests, and diets assessed at baseline and one year later. CMR score (CMRS) was computed by summing Z-scores of waist circumference, an average of systolic and diastolic blood pressure (SBP and DBP), fasting glucose, high-density lipoprotein cholesterol (HDL-C, multiplying by -1 ), and triglycerides. Machine learning was used to identify leading dietary determinants for CMR and an HDS was then computed.
\end{abstract}

Results: The nine leading predictors for CMRS were refined grains, seafood, fried foods, sugar-sweetened beverages, wheat, red meat other than pork, rice, fungi and algae, and roots and tubers with the contribution ranging from 3.9 to $19.6 \%$ of the total variance. Diets high in seafood, rice, and red meat other than pork but low in other six food groups were associated with a favorable change in CMRS. The HDS was computed based on these nine dietary factors. Children with HDS $\geq 8$ had a higher decrease in CMRS ( $\beta(95 \% \mathrm{Cl}):-1.02(-1.31,-0.73))$, BMl $(-0.08(-0.16,-0.00))$, SBP $(-0.46(-0.58,-0.34))$, DBP $(-0.46(-0.58,-0.34))$, mean arterial pressure $(-0.50(-$ $0.62,-0.38))$, fasting glucose $(-0.22(-0.32,-0.11))$, insulin $(-0.52(-0.71,-0.32))$, and HOMA-IR $(-0.55(-0.73,-$ $0.36)$ ) compared to those with HDS $\leqq 3$. Improved HDS during follow-up was associated with favorable changes in CMRS, BMI, percent body fat, SBP, DBP, mean arterial pressure, HDL-C, fasting glucose, insulin, and HOMA-IR.

\footnotetext{
* Correspondence: mags@bjmu.edu.cn

${ }^{8}$ Department of Nutrition and Food Hygiene, School of Public Health, Peking University, 38 Xue Yuan Road, Beijing 100191, China

Full list of author information is available at the end of the article
}

C C The Author(s). 2020 Open Access This article is licensed under a Creative Commons Attribution 4.0 International License, which permits use, sharing, adaptation, distribution and reproduction in any medium or format, as long as you give appropriate credit to the original author(s) and the source, provide a link to the Creative Commons licence, and indicate if changes were made. The images or other third party material in this article are included in the article's Creative Commons licence, unless indicated otherwise in a credit line to the material. If material is not included in the article's Creative Commons licence and your intended use is not permitted by statutory regulation or exceeds the permitted use, you will need to obtain permission directly from the copyright holder. To view a copy of this licence, visit http://creativecommons.org/licenses/by/4.0/ The Creative Commons Public Domain Dedication waiver (http://creativecommons.org/publicdomain/zero/1.0/) applies to the data made available in this article, unless otherwise stated in a credit line to the data. 
(Continued from previous page)

Conclusion: Diets high in seafood, rice, and red meat other than pork and low in refined grains, fried foods, sugarsweetened beverages, and wheat are leading healthy dietary factors for metabolic health in children. HDS is strongly predictive of CMR factors.

Keywords: Cardiometabolic risk factors, Leading dietary determinants, Healthy diet score, Machine learning, Children

\section{Introduction}

The pandemic and increasing trend of obesity-related cardiometabolic risk (CMR) factors are a public health challenge globally [1, 2]. Data from the China Health and Nutrition Survey (CHNS) in 2009 showed that there was a high prevalence of CMR factors in both children and adults [3], which imposes a tremendous burden on health care systems. Childhood CMR factors are highly likely to persist into adulthood and are associated with cardiovascular disease, diabetes, and mortality in the future [4-8]. Therefore, it is imperative to slow or reverse the increasing trend in the prevalence of CMR factors at an early stage of life $[9,10]$.

Diet is of paramount importance for the prevention of CMR factors [11]. Strong evidence from adults has shown that diets low in processed food, sugar-sweetened beverages (SSBs), and carbohydrate, and high in dairy and fish are associated with lower risks of cardiometabolic disorders including obesity, cardiovascular disease, diabetes, dyslipidemia, and hypertension [12, 13]. However, consumption of individual foods has not been demonstrated to be strongly predictive of CMR factors in children. A recent systematic review has shown that significant associations between dietary intakes and obesity-related CMR factors were observed in 19\% of the 81 included studies in children [14]. Previous studies are also limited by small sample sizes, cross-sectional design, or failure to adjust for important confounders. Although dietary patterns have been well linked to CMR factors in children in some countries [15-17], they cannot be applied to other populations given that a healthy diet pattern in one study can be hardly derived from other studies. For example, a healthy diet pattern in one study was high in vegetables, fruits, and dairy [15], while a healthy pattern in another study was high in vegetables, fruits, fish, crackers, and bread [17]. Diet indices have also been developed for diet quality assessment, however, these indices are shown to be weak predictors of CMR factors [18, 19]. Identifying leading dietary determinants for changes in CMR factors using new methods is urgent for targeting intervention priorities for the prevention of CMR in children. It is also important to create a healthy diet score (HDS) to predict CMR factors in children.

We used machine learning techniques to identify leading dietary determinants for changes in CMR factors in children based on longitudinal data. We then created an HDS based on the identified leading determinants to predict CMR factors.

\section{Methods \\ Participant selection}

The present analysis was based on a multicenter, randomized cluster controlled trial and the full description of the study has been published elsewhere [20]. Briefly, the study was conducted in six capital or province capital cities including Beijing, Shanghai, Chongqing, Jinan, Harbin, and Guangzhou. Data were collected at both baseline (May 2009) and follow-up (May 2010). Children in the intervention group received nutrition lectures (knowledge, attitudes, and dietary habits) as well as participated in two times of ten minutes or one time 20 min of Happy 10 program per day (involves various physical activities such as games, dances, and gymnastics, which were designed to stimulate children to enjoy physical activity). A total of 9901 children from 390 classes within 38 schools were screened for eligibility. Among 9867 children who were assessed at baseline, 8572 were reassessed at follow-up. Participants whose dietary intakes were not assessed, those who fell in the top $(3500 \mathrm{Kcal} /$ day $)$ or bottom $(300 \mathrm{Kcal} /$ day $)$ percentile of total energy intake, and who had missing values in all cardiometabolic measurements were excluded $(n=2896)$. A total of 5676 participants were included in the final analysis (Fig. 1).

The study protocol was approved by the Ethical Review Committee of the National Institute for Nutrition and Food Safety, Chinese Centre for Disease Control and Prevention. Written informed consent was obtained from the next of kin, carers, or guardians of all participants.

\section{Dietary assessment}

Dietary intake was assessed using 24-h diet recalls for three consecutive days including two weekdays and one weekend day in children in grades 2-5. Interviews were conducted by trained investigators. During the interview, samples of local household dishes and utensils (different sizes of bowls, plates, and spoons) were displayed to the children. They were then shown pictures of common foods eaten in these dishes or utensils to indicate portion size consumed. The interviewer and the tutor would 
9901 children were assessed for eligibility

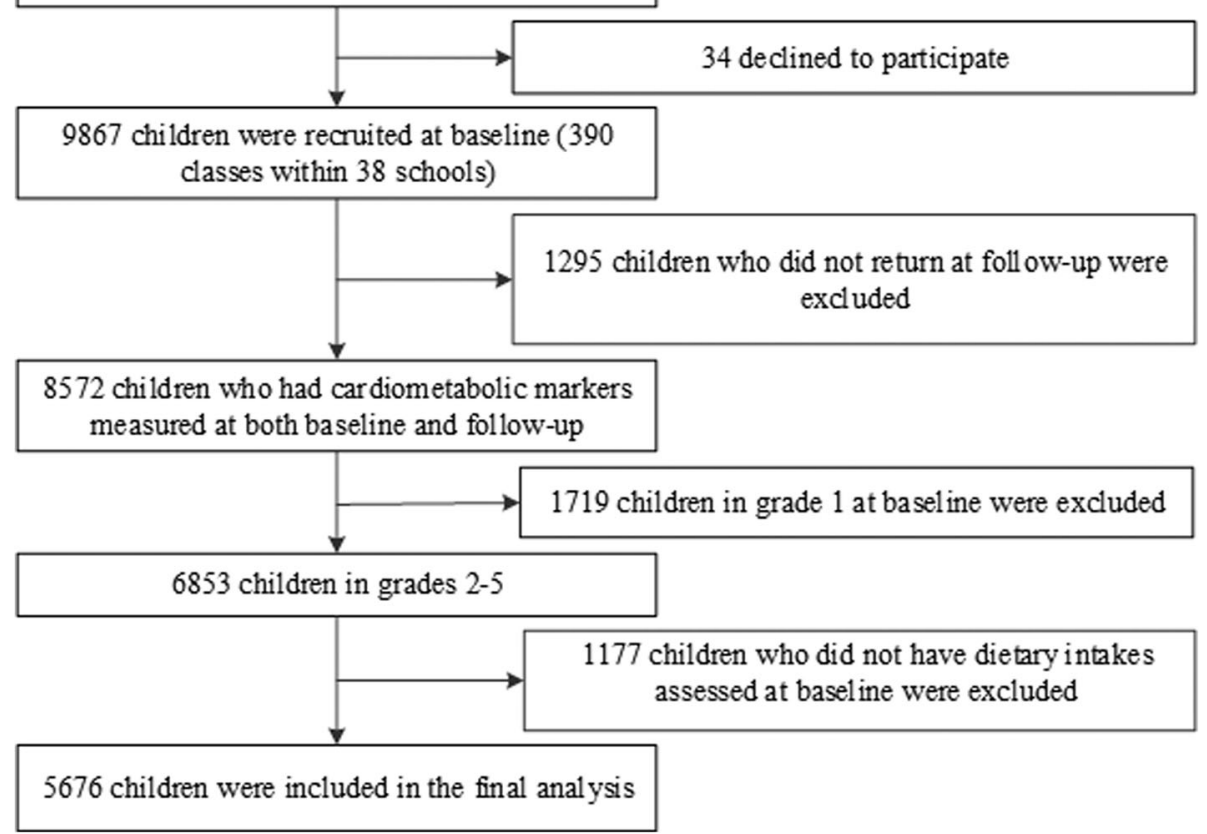

Fig. 1 Flowchart for population section

help children recall food intake at school while parents would help recall foods consumed at home.

A total of 1169 different food items were collected among all children and they were categorized into 26 groups according to nutrient contents as below: rice (boiled), wheat (such as steamed bun, noodles, and brans), refined grains (such as white breads, pizza, muffins, pancakes, and granola bar made by further processing grain powder), other cereals (such as corn, millet, and sorghum), fried foods, nuts and legumes (such as peanuts, walnuts, beans, and soybean products), starch roots and tubers, deep color vegetables, light color vegetables, edible fungi and algae (such as mushrooms, agaric, seaweed, and kelp), pickled vegetables (such as pickled mustard root, pickled sweet garlic, pickled cucumber, and pickled radish), fruits, pork, poultry, red meat other than pork (beef, lamb, other red meat), animal offal, processed meat (such as ham, beef jerky, and luncheon meat), seafood (such as fish, lobster, and crab), eggs, milk, yogurt, dairy product (such as milk powder and cheese), catsup and other sources, SSBs, candy and sugar, and dessert. Deep color vegetables were classified as carotene content $\geq 500 \mu \mathrm{g} / 100 \mathrm{~g}$ and light color vegetable with carotene $<500 \mu \mathrm{g} / 100 \mathrm{~g}$. Nutrients and energy intake was calculated based on the China Food Composition [21]. The average amount of food and nutrient intake per day was calculated and energy-adjusted food and nutrient consumption were computed as ([100 $\times$ weight in grams]/total energy intake in Kcal).

\section{Confounders}

Puberty status was recorded by investigators during the interview when physical examinations were conducted. Physical activity was assessed using a validated questionnaire in children, from which metabolic equivalent (MET) was calculated [22]. The questionnaire is a 39item self-administered questionnaire that captures the number of days in the past week, times per day, and the number of minutes per time engaging in the physical activity. MET was calculated according to the assigned metabolic values for each specified physical activity. Birthweight, household income, parental education, and parental height and weight were reported by parents using a self-administered questionnaire.

\section{Physical examinations and blood tests}

Physical examinations and blood tests (10-14 h fasting beforehand) were performed at both baseline and follow-up following standardized procedures.

Height was measured to the nearest $0.1 \mathrm{~cm}$ and weight to the nearest $0.1 \mathrm{~kg}$. Body mass index (BMI) was computed as weight in kilograms divided by the square of height in meters. Waist circumference (WC) was measured midway between the lowest rib and the superior border of the iliac crest on expiration to the nearest $0.1 \mathrm{~cm}$ and the average of two measurements was used.

Body composition was assessed using a single frequency $(50 \mathrm{~Hz})$ hand to foot bioelectrical impendence 
device (ImpDF50, Impedimed Pty Ltd., Qld, Australia). Body fat mass was computed using the prediction formula developed by Deurenberg et al. [23] and percent body fat (PBF) was calculated as fat mass divided by body weight.

Blood pressure was measured in the seated position using a mercury sphygmomanometer (XJ300/40-1, Made in Shanghai) by trained nurses with at least 10 min rest before the measurement. The first and the fifth Korotkoff sounds were used to represent the systolic and diastolic blood pressure (SBP and DBP). Three measurements were taken to the nearest two $\mathrm{mmHg}$ and the average of the last two measurements was used. Mean arterial pressure (MAP) was calculated as (DBP $+0.33 \times[$ SBP-DBP]).

Fasting glucose was measured using the glucoseoxidize method (Daiichi Pharmaceutical Co., Ltd., Tokyo, Japan) within four hours after the fasting blood sample was obtained. Fasting insulin was measured using the immunoenzymatic method (analyzer AXSYM, Abbott Co., Ltd., Japan). The homeostatic model assessment of insulin resistance (HOMA-IR) was computed as (fasting insulin $[\mu \mathrm{U} / \mathrm{L}] \times$ fasting glucose $[\mathrm{mg} / \mathrm{dL}]) / 405$.

Conventional enzymatic assays were used to measure levels of serum triglycerides (TG), total cholesterol (TC), high-density lipoprotein cholesterol (HDL-C), low-density lipoprotein cholesterol (LDL-C) with 7080 Automatic Analyzer (Daiichi Pharmaceutical Co., Ltd., Tokyo, Japan).

\section{Statistical analysis}

BMI, WC, PBF, SBP, DBP, MAP, TG, TC, HDL-C, LDL$C$, TG to HDL-C ratio, fasting glucose, insulin, and HOMA-IR were standardized (i.e. $Z$ scores were calculated: $\mathrm{Z}=$ (value-mean)/SD using sex- and age-specific means and SDs). CMR score (CMRS) was calculated by summing $\mathrm{Z}$ scores of $\mathrm{WC}$, the average of SBP and DBP, fasting glucose, HDL-C (multiplying by - 1), and TG [24].

We randomly selected $50 \%$ of all participants in the intervention study as training data and the remaining as testing data. We used three established machine learning models including multiple linear regression model, random forest, and gradient boost machine (GBM) to analyze the importance of 26 dietary predictors (baseline) for the change in CMRS based on the training data and compared the performance of these models based on the testing data. For multiple linear regression model, we selected Gaussian family distribution when established prediction model using machine learning techniques. The hyper-parameters alpha and lambda specify the regularization strength and the regularization distribution between L1 (LASSO) and (ridge regression) L2 penalties, respectively. The random forest algorithm is a supervised learning algorithm constructing an ensemble of decision-trees using randomly bootstrapping sample datasets and averaging predictions of its trees [25]. It applies a bagging method to ensemble multiple decision trees generated from subsets to reduce correlations among the constitute decision trees. In this study, we used the R-square to determine the best predicting variable and location for each tree split in our algorithm. We grew the forest with 500 trees and implemented a grid search to obtain optimal parameters including the number of variables randomly sampled as candidates at each split and the max depth of each tree (effectively the number of interactions are considered in the model) for the random forest.

GBM belongs to a family of machine learning approaches leveraging a boosting ensemble method. An ensemble of decision-trees was constructed using a weighted average of trees with more weight to those with a better performance [26]. GBM converts a weak original learning algorithm to a strong one by minimizing an exponential loss of the misclassification rate. A forest of 500 trees was applied and a grid search for model optimization was also conducted with the maximum number of models, the max depth of each tree, learning rate, row sample rate per tree, and column sample rate as hyper-parameters. Five-Fold cross-validation was applied to test if the models were overfitting. Regularization was conducted, and optimal parameters were used in modeling (Table S1). We realized these modeling exercises using the statistical software R 3.4.1 (toolbox h2o). Leading dietary factors were obtained according to their contribution derived from the machine learning method with the best performance.

A healthy diet score (HDS) was computed by summing sub-scores with each of the leading dietary predictors as one point according to their associations with CMRS. For example, more than the median intake of fruit was scored as 1 and equal or less as 0 , if fruit intake was inversely associated with CMRS. We also calculated a HDS by summing weighted sub-scores according to the contribution of the corresponding dietary predictors derived from the machine learning method. ANOVA for continuous variables and Chi-square tests for categorical variables were performed to compare the difference of baseline characteristics across HDS.

Since the interaction between intervention/sex and HDS for changes in most CMR factors was not significant (Table S2 and S3), we did the analysis for the association between HDS and CMR factors in the whole population.

The general linear regression model (GLM) was used to test the difference in changes in CMR factors between participants with different HDS. We tested the following models: 1) classes in schools were adjusted for as random effects and characteristics of the individuals including age, sex, and corresponding CMR factor at baseline as fixed effects; 2) model 1 plus intervention group, 
grade, puberty, BMI, physical activity, and intake of energy, fiber, vegetable, fruit, pork, legumes, and nuts at baseline; 3) model 2 plus birth weight, breastfeeding, household income, parental BMI and education. We used the Benjamin-Hochberg procedure to control the false discovery rate at level of $5 \%$ for multiple comparisons [27]. Bonferroni $P$-value adjustments were performed for all pairwise comparisons. The association between change in HDS and changes in CMR factors was also tested using GLM. Changes in CMR factors were calculated by subtracting the results at baseline from those at follow-up. HDS at follow-up was calculated based on the nine leading dietary determinants and improved HDS referred to an increase in HDS (subtracting HDS at baseline from that at follow-up). For individual CMR factors, a standardized mean difference of 0.2 , 0.5 , and $\geq 0.8$ represents a small, medium, and large effect size, respectively. As CMRS is the summing of Zscores of five components, a standardized mean difference of $1.0,2.5$, and $\geq 4.0$ represents a small, medium, and large effect size, respectively [28].

We did an interaction analysis to examine whether the association between HDS and CMRS was modified by sex, grade, birthweight, household income, parental BMI, and parental education.

We repeated the analysis for the association between HDS and changes in CMR factors in children in the control group. We also did external validation of our HDS in children aged 6-13 years from CHNS with diet and physical examinations measured in two or more surveys.

Analyses except modeling machine learning were performed using SAS version 9.4 (SAS Institute Inc.) and all $P$ values were two-sided.

\section{Results}

We included 5676 children ( $50.5 \%$ girls) aged $6-13$ years (mean \pm SD: $9.54 \pm 1.19$ ) in the final analysis. HDS was inversely associated with age, BMI, WC, PBF, and DBP at baseline and positively associated with TC, HDL-C, and LDL-C at baseline. There was not a significant association of HDS with CMRS at baseline. Higher HDS was associated with lower intake of energy, carbohydrate, fat, fiber, and iron and higher intake of protein, vitamin C, vitamin $\mathrm{E}$, and carotene (Table 1).

\section{Importance of contributors to CMRS}

Random Forest exhibited higher R-square compared with the other two machine learning models for CMRS (Table S4). Figure 2 depicts the leading predictors for CMRS as derived from Random Forest. The nine leading predictors for CMRS were refined grains, seafood, fried foods, SSBs, wheat, red meat other than pork, rice, fungi and algae, and roots and tubers with the contribution ranging from 3.9 to $19.6 \%$ of the total variance. These leading predictors were consistent with those identified by GBM and GLM (Table S5).

\section{Dietary intakes and CMRS and healthy diet score}

Diets low in refined grains, fried foods, SSBs, wheat, fungi and algae, roots and tubers and high in seafood, rice, and red meat other than pork were associated with a favorable change in CMRS (Table 2). HDS was then computed by summing sub-scores with each of the nine leading healthy factors as one point (according to their associations with CMRS): refined grains (<median), seafood (>median), fried foods $(<$ median), SSBs $(<$ median), wheat $(<$ median), red meat other than pork (>median), rice (>median), fungi and algae $(<$ median), and roots and tubers $(<$ median). HDS ranged from 0 to 9 with a higher level representing a healthier diet. HDS was also calculated by summing the weighted sub-scores according to the contribution derived from the Random Forest. The maximum sub-score of 1 was set at the levels of 0 (refined grains, fried foods, SSBs, wheat, fungi and algae, and roots and tubers) or above the 80th percentile (seafood, rice, and red meat other than pork) of the food intake. While the minimum score of 0 was set at the levels of above the 80th percentile (refined grains, fried foods, SSBs, wheat, fungi and algae, and roots and tubers) or 0 (seafood, rice, and red meat other than pork) of the food intake. Scores for the amounts between 0 and 1 were prorated linearly. The sub-scores were then weighted by multiplying the contribution (percentage of the total variance of the nine dietary predictors) of the corresponding dietary predictors (Table S6).

\section{Healthy diet score and CMR factors}

High HDS at baseline was associated with favorable changes in CMRS, BMI, PBF, SBP, DBP, MAP, HDL-C, fasting glucose, insulin, and HOMA-IR. There was a positive association between HDS at baseline and changes in TC and LDL-C (Table 3). High weighted HDS at baseline was associated with favorable changes in CMRS, BMI, PBF, SBP, DBP, MAP, HDL-C, fasting glucose, insulin, and HOMA-IR (Table S7). Improved HDS was associated with favorable changes in BMI, SBP, DBP, MAP, fasting glucose, insulin, HOMA-IR, and CMRS (Table S8).

\section{Moderation analysis}

The inverse association between HDS and CMRS was stronger in children whose parents had higher education (Fig. 3). No significant interaction between HDS and sex, grade, birthweight, household income, or parental BMI for change in CMRS was observed.

\section{Sensitivity analysis}

High HDS at baseline was associated with favorable changes in CMRS, PBF, SBP, DBP, MAP, HDL-C, TG, insulin, and HOMA-IR in the control group (Table S9). 
Table 1 Baseline characteristics by healthy diet score

\begin{tabular}{|c|c|c|c|c|c|c|c|}
\hline & \multicolumn{6}{|c|}{ Healthy Diet Score* } & \multirow[t]{2}{*}{$P$ value $^{\dagger}$} \\
\hline & $\leq 3(n=861)$ & $4(n=1021)$ & $5(n=1328)$ & $6(n=1420)$ & $7(n=773)$ & $\geq 8(n=299)$ & \\
\hline Age (years) & $9.75 \pm 1.29^{\ddagger}$ & $9.57 \pm 1.18$ & $9.49 \pm 1.15$ & $9.44 \pm 1.19$ & $9.56 \pm 1.11$ & $9.47 \pm 1.14$ & $<0.0001$ \\
\hline BMI $\left(\mathrm{kg} / \mathrm{m}^{2}\right)$ & $17.50 \pm 3.55$ & $17.23 \pm 3.21$ & $17.31 \pm 3.20$ & $17.04 \pm 3.09$ & $17.02 \pm 2.93$ & $16.79 \pm 2.87$ & $<0.0001$ \\
\hline WC (cm) & $59.30 \pm 9.50$ & $58.94 \pm 9.32$ & $58.67 \pm 8.76$ & $57.83 \pm 8.61$ & $58.04 \pm 8.19$ & $57.49 \pm 8.07$ & $<0.0001$ \\
\hline PBF (\%) & $24.65 \pm 4.65$ & $24.32 \pm 4.66$ & $24.22 \pm 4.91$ & $23.53 \pm 4.92$ & $23.26 \pm 4.84$ & $23.01 \pm 4.72$ & $<0.0001$ \\
\hline $\mathrm{SBP}(\mathrm{mm} \mathrm{Hg})$ & $101.21 \pm 11.09$ & $100.92 \pm 10.80$ & $100.37 \pm 10.89$ & $100.24 \pm 10.98$ & $100.54 \pm 10.61$ & $100.75 \pm 10.14$ & 0.11 \\
\hline $\mathrm{DBP}(\mathrm{mm} \mathrm{Hg})$ & $64.91 \pm 9.31$ & $64.23 \pm 9.38$ & $64.18 \pm 8.89$ & $63.81 \pm 9.09$ & $63.89 \pm 8.56$ & $64.00 \pm 8.89$ & 0.013 \\
\hline $\mathrm{TC}(\mathrm{mmol} / \mathrm{L})$ & $3.96 \pm 0.71$ & $3.97 \pm 0.73$ & $4.04 \pm 0.77$ & $4.15 \pm 0.83$ & $4.25 \pm 0.83$ & $4.28 \pm 0.77$ & $<0.0001$ \\
\hline $\mathrm{HDL}-\mathrm{C}(\mathrm{mmol} / \mathrm{L})$ & $1.46 \pm 0.31$ & $1.46 \pm 0.32$ & $1.45 \pm 0.29$ & $1.48 \pm 0.30$ & $1.51 \pm 0.30$ & $1.49 \pm 0.30$ & 0.0012 \\
\hline LDL-C (mmol/L) & $1.94 \pm 0.64$ & $2.02 \pm 0.60$ & $2.14 \pm 0.64$ & $2.20 \pm 0.63$ & $2.26 \pm 0.63$ & $2.27 \pm 0.58$ & $<0.0001$ \\
\hline TG (mmol/L) & $0.79 \pm 0.43$ & $0.80 \pm 0.41$ & $0.85 \pm 0.48$ & $0.84 \pm 0.46$ & $0.82 \pm 0.45$ & $0.78 \pm 0.39$ & 0.18 \\
\hline Fasting glucose (mmol/L) & $4.47 \pm 0.61$ & $4.46 \pm 0.60$ & $4.48 \pm 0.58$ & $4.55 \pm 0.53$ & $4.61 \pm 0.47$ & $4.62 \pm 0.42$ & $<0.0001$ \\
\hline CMRS & $-0.27 \pm 2.46$ & $-0.25 \pm 2.53$ & $-0.09 \pm 2.35$ & $-0.26 \pm 2.34$ & $-0.30 \pm 2.30$ & $-0.22 \pm 2.35$ & 0.86 \\
\hline Physical activity (MET/week) & $608.3 \pm 444.3$ & $621.4 \pm 490.8$ & $666.3 \pm 592.7$ & $620.0 \pm 586.1$ & $605.8 \pm 613.0$ & $676.4 \pm 723.9$ & 0.55 \\
\hline Energy (kcal/day) & $1268.6 \pm 529.1$ & $1281.9 \pm 594.2$ & $1326.8 \pm 626.0$ & $1274.8 \pm 582.0$ & $1217.1 \pm 560.3$ & $1152.5 \pm 523.4$ & 0.0018 \\
\hline Refined grains (gram/100 kcal/day) & $1.60 \pm 2.54$ & $1.62 \pm 3.63$ & $1.93 \pm 4.40$ & $3.21 \pm 6.18$ & $3.64 \pm 6.12$ & $3.39 \pm 6.22$ & $<0.0001$ \\
\hline Seafood (gram/100 kcal/day) & $0.44 \pm 1.61$ & $0.96 \pm 2.37$ & $1.56 \pm 2.93$ & $2.72 \pm 3.90$ & $4.19 \pm 4.97$ & $5.17 \pm 4.86$ & $<0.0001$ \\
\hline Fried foods (gram/100 kcal/day) & $1.96 \pm 2.37$ & $1.15 \pm 2.11$ & $0.66 \pm 1.85$ & $0.28 \pm 1.16$ & $0.12 \pm 0.62$ & $0.04 \pm 0.43$ & $<0.0001$ \\
\hline $\begin{array}{l}\text { Sugar-sweetened beverages } \\
\text { (gram/100 kcal/day) }\end{array}$ & $3.39 \pm 5.07$ & $2.84 \pm 5.37$ & $1.85 \pm 4.47$ & $1.28 \pm 4.14$ & $0.58 \pm 2.48$ & $0.23 \pm 2.09$ & $<0.0001$ \\
\hline Rice (gram/100 kcal/day) & $3.97 \pm 2.82$ & $4.98 \pm 4.19$ & $6.32 \pm 5.08$ & $9.08 \pm 6.73$ & $11.21 \pm 8.67$ & $12.60 \pm 6.61$ & $<0.0001$ \\
\hline Wheat (gram/100 kcal/day) & $7.28 \pm 3.99$ & $6.98 \pm 4.48$ & $6.41 \pm 5.06$ & $5.03 \pm 4.91$ & $3.47 \pm 3.79$ & $2.33 \pm 2.44$ & $<0.0001$ \\
\hline Fungi and algae (gram/100 kcal/day) & $0.95 \pm 1.32$ & $0.69 \pm 1.29$ & $0.45 \pm 1.25$ & $0.32 \pm 0.85$ & $0.21 \pm 0.77$ & $0.08 \pm 0.37$ & $<0.0001$ \\
\hline Roots and tubers (gram/100 kcal/day) & $2.76 \pm 2.62$ & $2.30 \pm 3.01$ & $1.71 \pm 2.89$ & $1.19 \pm 2.56$ & $0.72 \pm 1.92$ & $0.39 \pm 1.23$ & $<0.0001$ \\
\hline $\begin{array}{l}\text { Red meat other than pork } \\
\text { (gram/100 kcal/day) }\end{array}$ & $0.24 \pm 0.94$ & $0.41 \pm 1.27$ & $0.67 \pm 1.88$ & $1.00 \pm 2.29$ & $1.30 \pm 2.31$ & $2.06 \pm 2.95$ & $<0.0001$ \\
\hline Protein intake (g/100 Kcal/day) & $3.97 \pm 0.81$ & $4.10 \pm 0.97$ & $4.21 \pm 1.04$ & $4.39 \pm 1.19$ & $4.82 \pm 1.22$ & $5.17 \pm 1.38$ & $<0.0001$ \\
\hline Fat intake (g/100 Kcal/day) & $3.03 \pm 1.07$ & $3.03 \pm 1.16$ & $2.92 \pm 1.23$ & $2.92 \pm 1.21$ & $2.93 \pm 1.07$ & $2.92 \pm 0.99$ & 0.0084 \\
\hline Carbohydrate intake (g/100 Kcal/day) & $14.40 \pm 2.58$ & $14.24 \pm 2.83$ & $14.35 \pm 3.07$ & $14.20 \pm 3.13$ & $13.74 \pm 2.90$ & $13.35 \pm 2.93$ & $<0.0001$ \\
\hline Fibre intake (g/100 Kcal/day) & $0.65 \pm 0.36$ & $0.58 \pm 0.39$ & $0.52 \pm 0.32$ & $0.48 \pm 0.30$ & $0.46 \pm 0.25$ & $0.43 \pm 0.23$ & $<0.0001$ \\
\hline Vitamin C intake (mg/100 Kcal/day) & $3.15 \pm 2.11$ & $3.23 \pm 2.58$ & $3.11 \pm 2.55$ & $3.27 \pm 2.88$ & $3.45 \pm 2.69$ & $3.41 \pm 2.57$ & 0.0164 \\
\hline Vitamin E intake (mg/100 Kcal/day) & $0.31 \pm 0.26$ & $0.29 \pm 0.21$ & $0.26 \pm 0.16$ & $0.26 \pm 0.17$ & $0.25 \pm 0.15$ & $0.26 \pm 0.16$ & $<0.0001$ \\
\hline Carotene intake (ug/100 Kcal/day) & $73.42 \pm 64.62$ & $73.52 \pm 83.18$ & $72.64 \pm 79.47$ & $79.83 \pm 95.19$ & $83.16 \pm 99.95$ & $78.82 \pm 82.90$ & 0.0055 \\
\hline Magnesium intake (mg/100 Kcal/day) & $15.19 \pm 3.51$ & $14.94 \pm 3.59$ & $14.77 \pm 3.78$ & $14.72 \pm 3.77$ & $15.12 \pm 3.91$ & $15.44 \pm 4.15$ & 0.99 \\
\hline Potassium intake (mg/100 Kcal/day) & $102.00 \pm 26.22$ & $100.95 \pm 32.25$ & $97.17 \pm 31.47$ & $99.02 \pm 35.06$ & $102.44 \pm 33.10$ & $104.67 \pm 32.89$ & 0.55 \\
\hline Phosphorus intake (mg/100 Kcal/day) & $58.39 \pm 10.29$ & $59.32 \pm 12.05$ & $60.12 \pm 13.49$ & $62.13 \pm 15.07$ & $65.51 \pm 14.03$ & $68.70 \pm 16.19$ & $<0.0001$ \\
\hline Calcium intake (mg/100 Kcal/day) & $30.84 \pm 13.12$ & $30.61 \pm 14.84$ & $29.41 \pm 15.20$ & $30.01 \pm 18.41$ & $30.53 \pm 15.54$ & $31.44 \pm 15.90$ & 0.90 \\
\hline Iron intake (mg/100 Kcal/day) & $1.39 \pm 1.05$ & $1.24 \pm 0.88$ & $1.14 \pm 0.54$ & $1.14 \pm 0.52$ & $1.14 \pm 0.35$ & $1.16 \pm 0.29$ & $<0.0001$ \\
\hline Sex & & & & & & & 0.0001 \\
\hline Boys & $384(44.6)^{\S}$ & $481(47.1)$ & $654(49.2)$ & $708(49.9)$ & $414(53.6)$ & $155(51.8)$ & \\
\hline Girls & $477(55.4)$ & $540(52.9)$ & $674(50.8)$ & $712(50.1)$ & $359(46.4)$ & $144(48.2)$ & \\
\hline Grade & & & & & & & 0.0001 \\
\hline Two & $217(25.2)$ & $276(27.0)$ & $385(29.0)$ & $431(30.4)$ & $212(27.4)$ & $96(32.1)$ & \\
\hline Three & $209(24.3)$ & $291(28.5)$ & $381(28.7)$ & $380(26.8)$ & $205(26.5)$ & $73(24.4)$ & \\
\hline Four & $231(26.8)$ & $267(26.2)$ & $362(27.3)$ & $384(27.0)$ & $231(29.9)$ & $88(29.4)$ & \\
\hline
\end{tabular}


Table 1 Baseline characteristics by healthy diet score (Continued)

\begin{tabular}{|c|c|c|c|c|c|c|c|}
\hline & Healthy Diet & ore* & & & & & $P$ value $^{\dagger}$ \\
\hline & $\leq 3(n=861)$ & $4(n=1021)$ & $5(n=1328)$ & $6(n=1420)$ & $7(n=773)$ & $\geq 8(n=299)$ & \\
\hline Five & $204(23.7)$ & 187 (18.3) & $200(15.1)$ & 225 (15.8) & $125(16.2)$ & $42(14.0)$ & \\
\hline Puberty & & & & & & & 0.12 \\
\hline Yes & $782(90.8)$ & $931(91.2)$ & 1239 (93.3) & $1316(92.7)$ & 711 (92.0) & $278(93.0)$ & \\
\hline No & $79(9.2)$ & $90(8.8)$ & $89(6.7)$ & $104(7.3)$ & $62(8.0)$ & $21(7.0)$ & \\
\hline Birth weight & & & & & & & 0.42 \\
\hline$<2500 \mathrm{~g}$ & $31(3.6)$ & $27(2.6)$ & $50(3.8)$ & $56(3.9)$ & $23(3.0)$ & $10(3.3)$ & \\
\hline $2500-3999 \mathrm{~g}$ & $696(80.8)$ & $793(77.7)$ & $1048(78.9)$ & $1114(78.5)$ & $635(82.1)$ & $244(81.6)$ & \\
\hline$\geq 4000 \mathrm{~g}$ & $77(8.9)$ & 118 (11.6) & $129(9.7)$ & $119(8.4)$ & $47(6.1)$ & $21(7.0)$ & \\
\hline Missing & $57(6.6)$ & $83(8.1)$ & $101(7.6)$ & $131(9.2)$ & $68(8.8)$ & $24(8.0)$ & \\
\hline Mother's BMI & & & & & & & 0.0008 \\
\hline$<24 \mathrm{~kg} / \mathrm{m}^{2}$ & $641(74.4)$ & $765(74.9)$ & $980(73.8)$ & $1113(78.4)$ & $587(75.9)$ & $258(86.3)$ & \\
\hline $24-27.9 \mathrm{~kg} / \mathrm{m}^{2}$ & 159 (18.5) & $176(17.2)$ & $235(17.7)$ & $203(14.3)$ & $136(17.6)$ & $25(8.4)$ & \\
\hline$\geq 28 \mathrm{~kg} / \mathrm{m}^{2}$ & $24(2.8)$ & $28(2.7)$ & $40(3.0)$ & $22(1.5)$ & $15(1.9)$ & $6(2.0)$ & \\
\hline Missing & $37(4.3)$ & $52(5.1)$ & $73(5.5)$ & $82(5.8)$ & $35(4.5)$ & $10(3.3)$ & \\
\hline Father's BMI & & & & & & & $<0.0001$ \\
\hline$<24 \mathrm{~kg} / \mathrm{m}^{2}$ & $433(50.3)$ & $515(50.4)$ & $641(48.3)$ & $769(54.2)$ & $459(59.4)$ & $173(57.9)$ & \\
\hline $24-27.9 \mathrm{~kg} / \mathrm{m}^{2}$ & $307(35.7)$ & $346(33.9)$ & $494(37.2)$ & 477 (33.6) & $217(28.1)$ & $102(34.1)$ & \\
\hline$\geq 28 \mathrm{~kg} / \mathrm{m}^{2}$ & $84(9.8)$ & $108(10.6)$ & $120(9.0)$ & $92(6.5)$ & $62(8.0)$ & $14(4.7)$ & \\
\hline Missing & $37(4.3)$ & $52(5.1)$ & $73(5.5)$ & $82(5.8)$ & $35(4.5)$ & $10(3.3)$ & \\
\hline Mother's education & & & & & & & $<0.0001$ \\
\hline$<7$ years & $132(15.3)$ & $135(13.2)$ & $151(11.4)$ & $163(11.5)$ & $65(8.4)$ & $11(3.7)$ & \\
\hline $7-12$ years & $530(61.6)$ & $606(59.4)$ & $804(60.5)$ & $835(58.8)$ & $464(60.0)$ & $191(63.9)$ & \\
\hline$\geq 13$ years & $144(16.7)$ & $205(20.1)$ & $274(20.6)$ & $315(22.2)$ & $188(24.3)$ & $82(27.4)$ & \\
\hline Missing & $55(6.4)$ & $75(7.3)$ & $99(7.5)$ & $107(7.5)$ & $56(7.2)$ & $15(5.0)$ & \\
\hline Father's education & & & & & & & $<0.0001$ \\
\hline$<7$ years & $80(9.3)$ & $69(6.8)$ & $101(7.6)$ & $80(5.6)$ & $36(4.7)$ & $7(2.3)$ & \\
\hline $7-12$ years & $552(64.1)$ & $658(64.4)$ & $835(62.9)$ & $851(59.9)$ & $467(60.4)$ & $194(64.9)$ & \\
\hline$\geq 13$ years & $180(20.9)$ & $223(21.8)$ & $297(22.4)$ & $385(27.1)$ & $214(27.7)$ & $85(28.4)$ & \\
\hline Missing & $49(5.7)$ & $71(7.0)$ & $95(7.2)$ & $104(7.3)$ & $56(7.2)$ & $13(4.3)$ & \\
\hline Household income per month & & & & & & & $<0.0001$ \\
\hline$<750 \mathrm{RMB}$ & $108(12.5)$ & $145(14.2)$ & $153(11.5)$ & $149(10.5)$ & $67(8.7)$ & $13(4.3)$ & \\
\hline 751-1500 RMB & $317(36.8)$ & 339 (33.2) & $420(31.6)$ & $414(29.2)$ & $199(25.7)$ & $70(23.4)$ & \\
\hline $1501-2500 \mathrm{RMB}$ & $217(25.2)$ & $246(24.1)$ & $336(25.3)$ & 335 (23.6) & $204(26.4)$ & $91(30.4)$ & \\
\hline$\geq 2501 \mathrm{RMB}$ & $150(17.4)$ & $208(20.4)$ & $307(23.1)$ & $400(28.2)$ & $243(31.4)$ & $110(36.8)$ & \\
\hline Missing & $69(8.0)$ & $83(8.1)$ & $112(8.4)$ & $122(8.6)$ & $60(7.8)$ & $15(5.0)$ & \\
\hline Intervention & & & & & & & $<0.0001$ \\
\hline No & $288(33.4)$ & $440(43.1)$ & $695(52.3)$ & 729 (51.3) & $361(46.7)$ & 116 (38.8) & \\
\hline Yes & $573(66.6)$ & $581(56.9)$ & $633(47.7)$ & $691(48.7)$ & $412(53.3)$ & $183(61.2)$ & \\
\hline
\end{tabular}

BMI, body mass index; CMRS, cardiometabolic risk score; DBP, diastolic blood pressure; HDL-C, high-density lipoprotein cholesterol; LDL-C, low-density lipoprotein cholesterol; MAP, mean arterial pressure; SBP, systolic blood pressure; TC, total cholesterol; TG, triglyceride

*HDS was computed by summing sub-scores with each of the leading dietary predictors as one point according to their associations with CMRS. For example,

more than the median intake of fruit was scored as 1 and equal or less as 0 , if fruit intake was inversely associated with CMRS

${ }^{\dagger}$ ANOVA was used to test the difference of continuous variables across healthy diet score and Chi-square for categorical variables

${ }^{\ddagger}$ All such data were mean \pm standard deviation

${ }^{\S}$ All such data were frequency (percentage) 


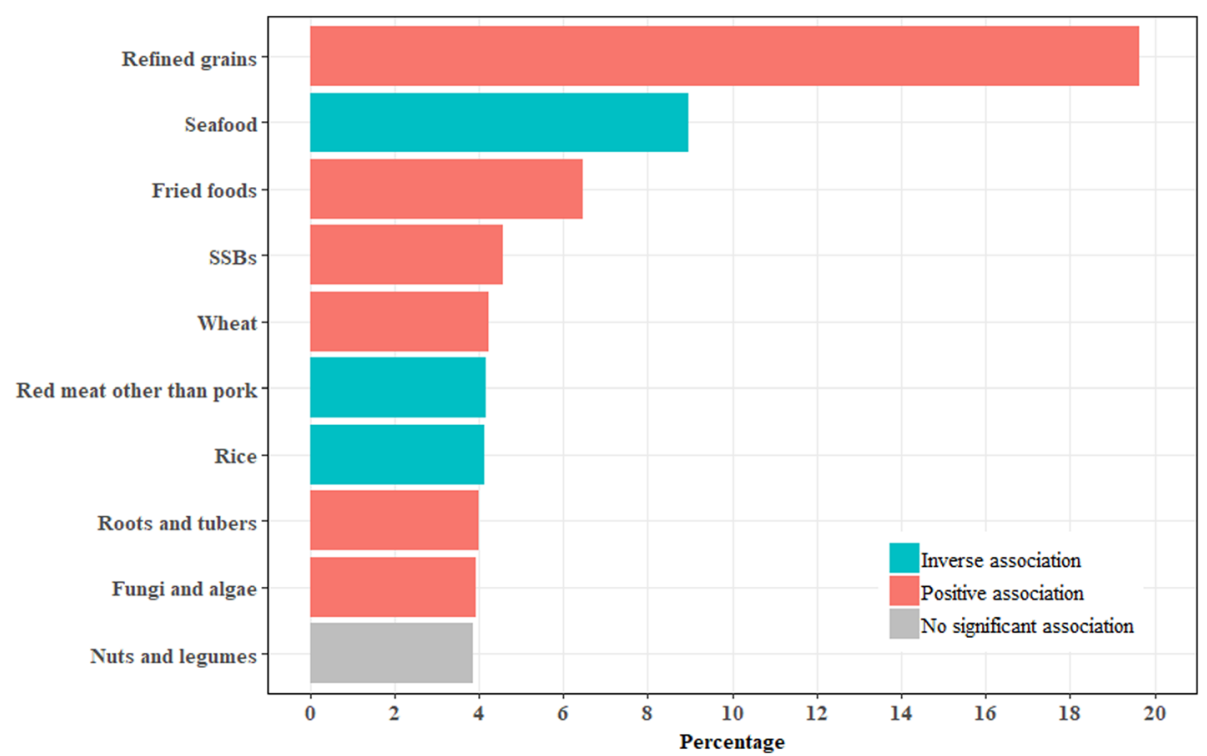

Fig. 2 Leading dietary determinants for changes in cardiometabolic risk scores in children. This figure shows the contribution of the total variance in percentage by leading dietary determinants (selected from 26 food groups). Machine learning models including general linear regression model, random forest, and gradient boost machine were used to analyze the importance of dietary predictors for CMRS. Random forest had the highest prediction performance and this figure shows the leading dietary determinants derived from the random forest

\section{External validation}

We examined the association of HDS with available CMR factors among 4530 children aged 6-13 years from CHNS. Baseline HDS was inversely associated with BMI, WC, SBP, DBP, and MAP at baseline and the change in DBP (Table S10).

\section{Discussion}

In this longitudinal analysis of children with large sample size, we found the nine leading healthy dietary determinants for CMRS were diets low in refined grains, fried foods, SSBs, wheat, fungi and algae, and roots and tubers, and high in seafood, rice, and red meat other than pork. We created an HDS based on these leading determinants that were shown to be a strong predictor for changes in 10 out of 14 CMR factors examined. The inverse association between HDS and CMRS was more likely to be evident in children whose parents had high education. The predictive ability of our HDS on several CMRS factors was validated in children from CHNS.

Previous studies have shown that diets high in glycemic index are associated with high CMR in children [29]. Our findings agree with these studies showing that high consumption of refined grains, fried foods, SSBs, roots and tubers, or wheat was associated with a higher increase in CMRS. The positive association between SSBs intake and CMR factors has been reported in many studies $[16,17,30]$. Although refined grains and wheat were not linked to CMR factors in children, their harmful effect on CMR has been reported in adults [31].
Foods being fried have lower nutrients and higher energy density than those being boiled or steamed [32, 33]. Several cohort studies in adults showed that higher consumption of fried foods was associated with an increased risk of obesity, type 2 diabetes, and cardiovascular diseases [34, 35]. Our study supports the dietary guidelines that diets low in glycemic index are beneficial for the prevention of CMR factors.

Seafood, rice, and red meat other than pork are major sources of protein that plays an important role in child growth and development. High consumption of fish has been recommended for the prevention of CMR factors in adults because fish is rich in protein, omega- 3 fatty acids, and minerals $[12,13]$. Our further analysis shows that red meat other than pork intake was only significantly associated with two (pork and milk) out of 25 food groups (Table S11). The intake of pork and milk was not a significant predictor of CMRS suggesting that the red meat other than pork intake was independently associated with CMRS. Processed but not unprocessed red meat is associated with an increased risk of obesity and related CMR in previous studies suggesting that unprocessed red meat other than pork may be considered as part of a healthy balanced diet in children considering its high contents in protein [36]. Compared with the harmful effect of high wheat intake, high rice (white and brown) intake resulted in a beneficial change in CMRS in our study, which may be partly due to the difference in nutrient composition between rice and wheat [21]. The divergent associations of rice and wheat intake with 
Table 2 Changes in cardiometabolic risk score during follow-up associated with dietary intakes at baseline

\begin{tabular}{|c|c|c|c|}
\hline & $\begin{array}{l}\text { Low intake } \\
\text { (gram/100 kcal/day) }\end{array}$ & $\begin{array}{l}\text { High intake } \\
\text { (gram/100 kcal/day) }\end{array}$ & $P$-value* \\
\hline Refined grains & 0 & $>0$ & \\
\hline Participants & 1453 & 3361 & \\
\hline $\mathrm{CMRS}^{\dagger}$, Model $1^{\ddagger}$ & $-0.24 \pm 0.12^{\S}$ & $-0.03 \pm 0.12$ & 0.0024 \\
\hline CMRS, Model 2 & $-0.12 \pm 0.12$ & $0.07 \pm 0.11$ & 0.0074 \\
\hline CMRS, Model 3 & $0.01 \pm 0.14$ & $0.21 \pm 0.14$ & 0.0058 \\
\hline Seafood & 0 & $>0$ & \\
\hline Participants & 2571 & 2243 & \\
\hline CMRS, Model 1 & $0.09 \pm 0.11$ & $-0.37 \pm 0.12$ & $<0.0001$ \\
\hline CMRS, Model 2 & $0.22 \pm 0.11$ & $-0.25 \pm 0.11$ & $<0.0001$ \\
\hline CMRS, Model 3 & $0.32 \pm 0.14$ & $-0.14 \pm 0.14$ & $<0.0001$ \\
\hline Fried wheat/rice & 0 & $>0$ & \\
\hline Participants & 3892 & 922 & \\
\hline CMRS, Model 1 & $-0.22 \pm 0.12$ & $0.34 \pm 0.13$ & $<0.0001$ \\
\hline CMRS, Model 2 & $-0.09 \pm 0.11$ & $0.34 \pm 0.13$ & $<0.0001$ \\
\hline CMRS, Model 3 & $0.04 \pm 0.14$ & $0.45 \pm 0.15$ & $<0.0001$ \\
\hline SSBS & 0 & $>0$ & \\
\hline Participants & 3472 & 1342 & \\
\hline CMRS, Model 1 & $-0.17 \pm 0.12$ & $0.07 \pm 0.13$ & 0.0008 \\
\hline CMRS, Model 2 & $-0.05 \pm 0.11$ & $0.18 \pm 0.12$ & 0.0007 \\
\hline CMRS, Model 3 & $0.08 \pm 0.14$ & $0.33 \pm 0.15$ & 0.0004 \\
\hline Wheat & $\leqq 4.66$ & $>4.66$ & \\
\hline Participants & 3048 & 1766 & \\
\hline CMRS, Model 1 & $-0.21 \pm 0.12$ & $0.07 \pm 0.12$ & $<0.0001$ \\
\hline CMRS, Model 2 & $-0.05 \pm 0.11$ & $0.10 \pm 0.12$ & 0.0182 \\
\hline CMRS, Model 3 & $0.08 \pm 0.14$ & $0.22 \pm 0.14$ & 0.0433 \\
\hline Red meat other than pork & $\leqq 0.01$ & $>0.01$ & \\
\hline Participants & 3394 & 1420 & \\
\hline CMRS, Model 1 & $-0.03 \pm 0.12$ & $-0.28 \pm 0.12$ & 0.0005 \\
\hline CMRS, Model 2 & $0.10 \pm 0.11$ & $-0.19 \pm 0.12$ & $<0.0001$ \\
\hline CMRS, Model 3 & $0.23 \pm 0.14$ & $-0.05 \pm 0.14$ & $<0.0001$ \\
\hline Rice & $\leqq 5.99$ & $>5.99$ & \\
\hline Participants & 1109 & 3705 & \\
\hline CMRS, Model 1 & $0.33 \pm 0.13$ & $-0.25 \pm 0.12$ & $<0.0001$ \\
\hline CMRS, Model 2 & $0.46 \pm 0.13$ & $-0.12 \pm 0.11$ & $<0.0001$ \\
\hline CMRS, Model 3 & $0.54 \pm 0.15$ & $-0.01 \pm 0.14$ & $<0.0001$ \\
\hline Root and tuber & $\leqq 2.29$ & $>2.29$ & \\
\hline Participants & 2711 & 2103 & \\
\hline CMRS, Model 1 & $-0.14 \pm 0.12$ & $0.00 \pm 0.13$ & 0.0635 \\
\hline CMRS, Model 2 & $-0.00 \pm 0.11$ & $0.05 \pm 0.12$ & 0.41 \\
\hline CMRS, Model 3 & $0.14 \pm 0.14$ & $0.17 \pm 0.14$ & 0.63 \\
\hline Fungi and mushroom & 0 & $>0$ & \\
\hline Participants & 3244 & 1570 & \\
\hline CMRS, Model 1 & $-0.16 \pm 0.12$ & $0.03 \pm 0.12$ & 0.0058 \\
\hline
\end{tabular}


Table 2 Changes in cardiometabolic risk score during follow-up associated with dietary intakes at baseline (Continued)

\begin{tabular}{clll}
\hline & $\begin{array}{l}\text { Low intake } \\
\text { (gram/100 kcal/day) }\end{array}$ & $\begin{array}{l}\text { High intake } \\
\text { (gram/100 kcal/day) }\end{array}$ & $\begin{array}{c}\text {-value* } \\
\text { CMRS, Model 2 }\end{array}$ \\
CMRS, Model 3 & $-0.04 \pm 0.11$ & $0.12 \pm 0.12$ & 0.0195 \\
Nuts and legumes & $0.10 \pm 0.14$ & $0.25 \pm 0.14$ & 0.0212 \\
Participants & 0 & $>0$ & 2868 \\
CMRS, Model 1 & 1946 & $-0.07 \pm 0.12$ & 0.17 \\
CMRS, Model 2 & $-0.16 \pm 0.12$ & $0.02 \pm 0.11$ & 0.79 \\
CMRS, Model 3 & $-0.00 \pm 0.11$ & $0.15 \pm 0.14$ & 0.78 \\
\hline
\end{tabular}

"The change in CMRS was calculated by subtracting the result at baseline from that at follow-up

${ }^{\dagger}$ GLM was used to estimate multivariable-adjusted means and standard errors of cardiometabolic risk factors between quintiles. Benjamin-Hochberg's procedure was used to control the false discovery rate at level $5 \%$ for multiple comparisons with the P-value cut-off point of significance was 0.0233 for change in CMRS (Model 3)

${ }^{\ddagger}$ Model 1 was adjusted for classes in school as clustering effects and characteristics of individuals including age, sex, and corresponding CMR factor at baseline as fixed effects; Model 2 was adjusted for Model 1 plus puberty, grade, intervention, BMI, physical activity, and energy intake at baseline as fixed effects; Model 3 was adjusted for Model 2 plus birthweight, household income, mother's education, father's education, mother's BMI, and father's BMI as fixed effects

${ }^{\S}$ All these data are means \pm standard errors of change in CMRS

CMRS may also be attributable to the fact that they are associated with different dietary patterns. For example, we found high rice intake was associated with a higher intake of vegetables, fish, and poultry and a lower intake of fried foods, beverages, refined grains, and edible fungus and algae (Table S12). In contrast, high wheat intake was associated with a higher intake of fried foods, refined grains, roots and tubers, and a lower intake of fish, pork, milk, and vegetables (Table S13). Our findings highlight the importance of high consumption of seafood, rice, and red meat other than pork on the prevention of CMR factors in children.

The association between mushroom consumption and CMR factors is inconsistent between studies with the largest longitudinal study showing no significant association $[37,38]$. The association of edible fungus and algae with CMR is less known. The positive association of fungi and algae with CMR factors in our study may be partly attributed to the harmful constituents in some of them [39]. However, more research needs to warrant our findings.

Dietary patterns derived by posterior methods including principal component analysis, cluster analysis, and latent class analysis have been linked to CMR factors in children $[15-17,40]$. These studies showed that Western dietary pattern, high energy-dense pattern, or sweet dietary pattern were associated with high CMR [15-17], whereas vegetable and the wholemeal pattern was associated with favorable changes in CMR factors [40]. Although these findings may imply which food groups are associated with CMR factors, these dietary patterns can hardly be obtained in other studies. In contrast, priori patterns based on dietary guidelines may be applied to different studies and the findings are comparable [18]. An inverse association between adherence to Dietary Approaches to Stop Hypertension (DASH)
Dietary Pattern or Mediterranean pattern and CMR has been observed in some studies [41, 42], but not in other studies [18, 43]. Therefore, establishing an efficient HDS based on evidence to predict CMR factors in children is urgent. Our HDS created based on the leading determinants of CMRS was strongly associated with 10 out of 14 CMR factors. Although no significant association of baseline HDS with baseline CMRS was observed, both high baseline HDS and improved HDS were associated with favorable changes in most CMR factors in our study. Furthermore, validation analysis in children from CHNS showed that higher baseline HDS was associated with lower BMI, WC, SBP, DBP, and MAP in the crosssectional analysis and a lower increase in DBP only in the longitudinal analysis. The weak association between HDS and CMR factors in the longitudinal analysis might be due to the small variation of HDS and small available sample size in some HDS subgroups. We found higher parental education and higher HDS resulted in more decrease in CMRS suggesting the importance of the involvement of parents with high education and children whose parents with low education are more needed in care.

The strengths of the present study included the large sample size and the measurement of multiple CMR factors and dietary intakes assessed at both baseline and follow-up. To our knowledge, this is the first study to identify leading dietary determinants of CMRS in children using machine learning techniques. We also created an HDS based on medians of leading determinants that were strongly predictive of most CMR factors. This score was also validated in children from CHNS. The study has several limitations. Firstly, $24 \mathrm{~h}$ of food records are limited by not accounting for seasonal variation of dietary intakes especially fruits and vegetables. However, the dietary intakes are comparable between individuals 


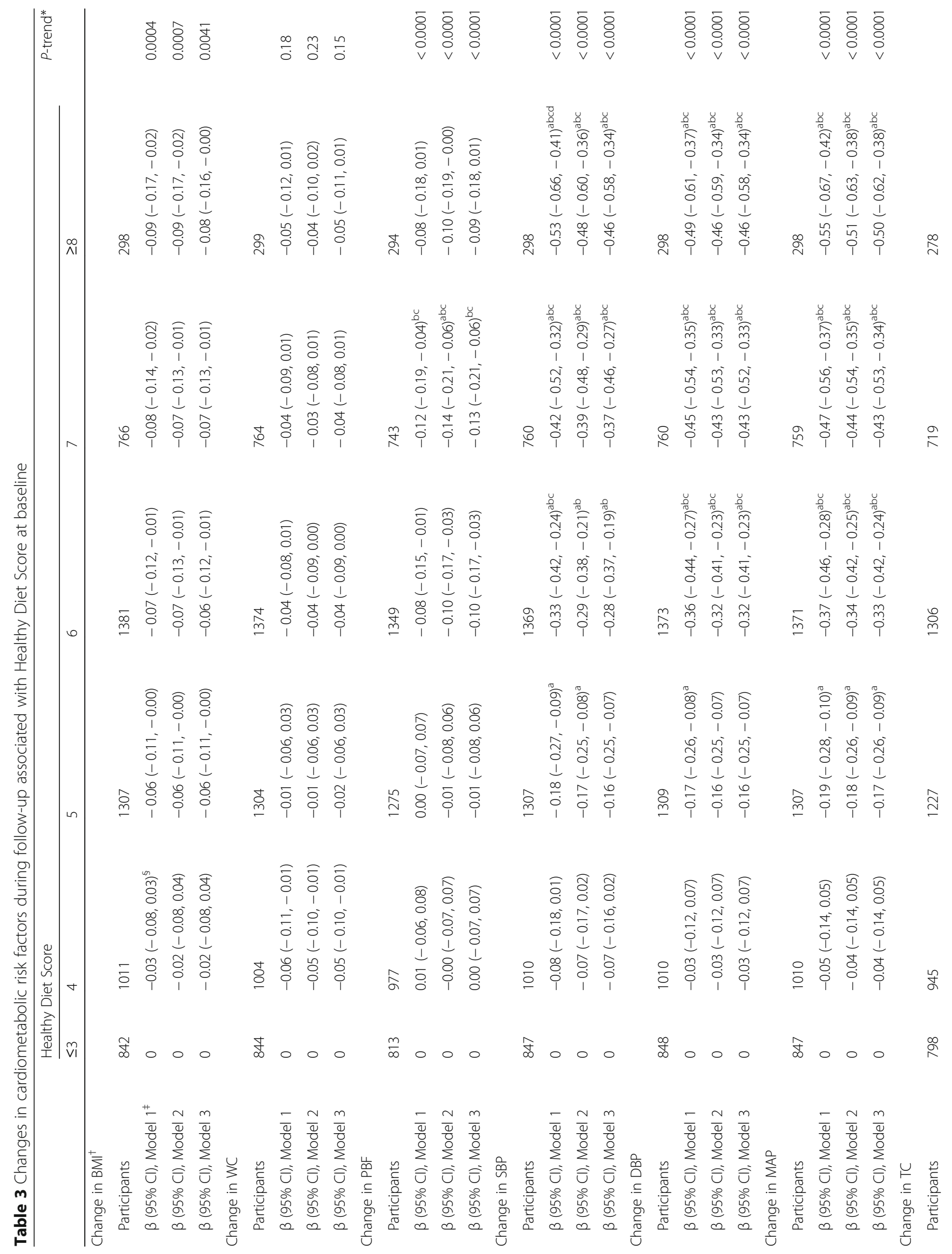




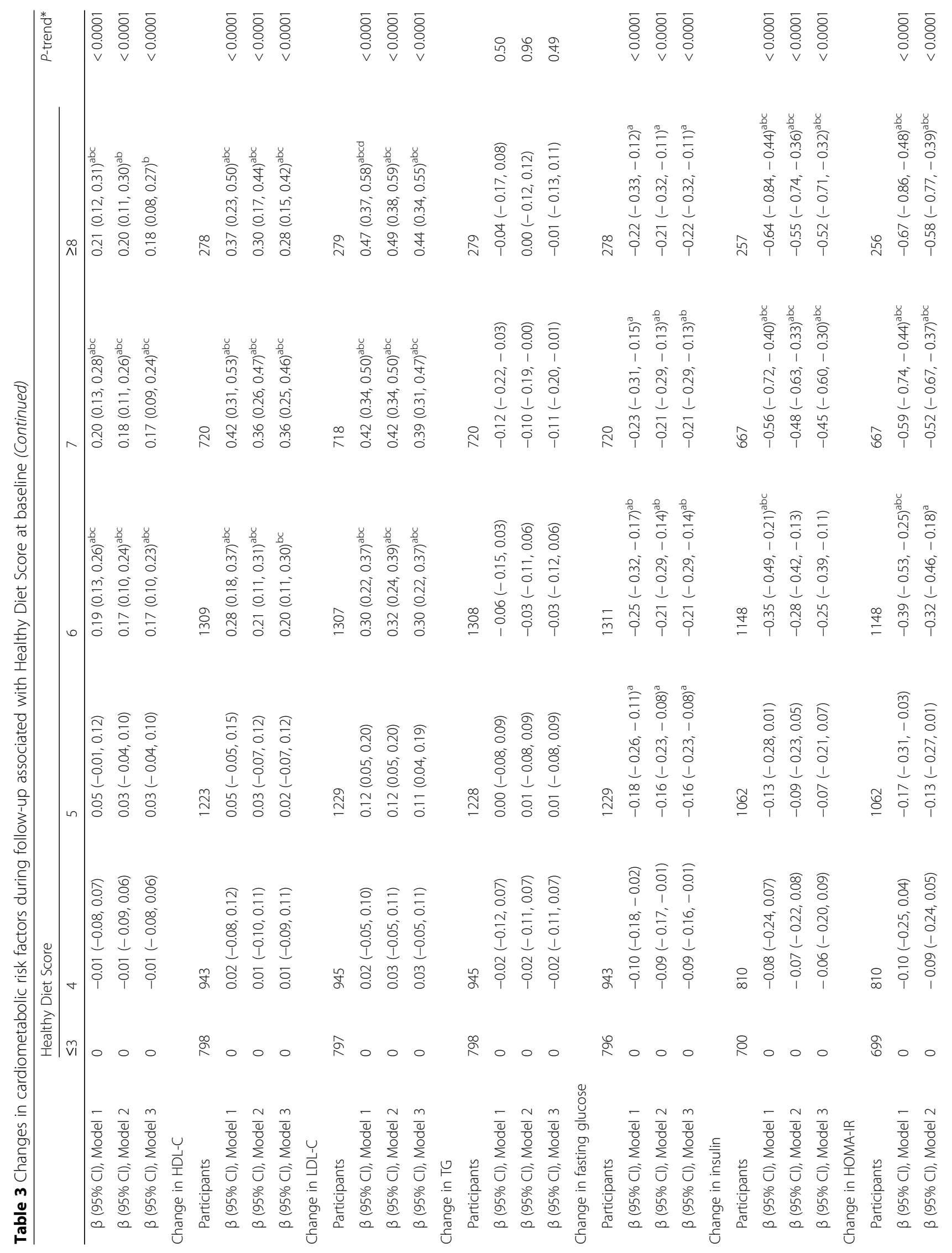




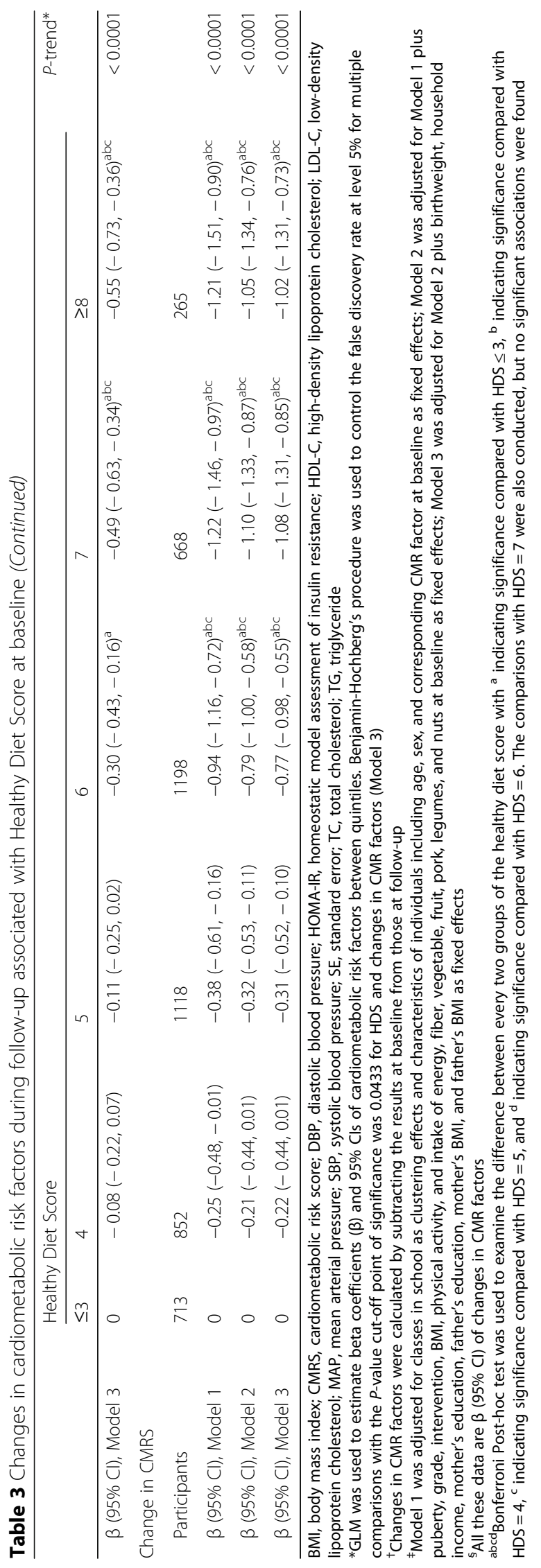



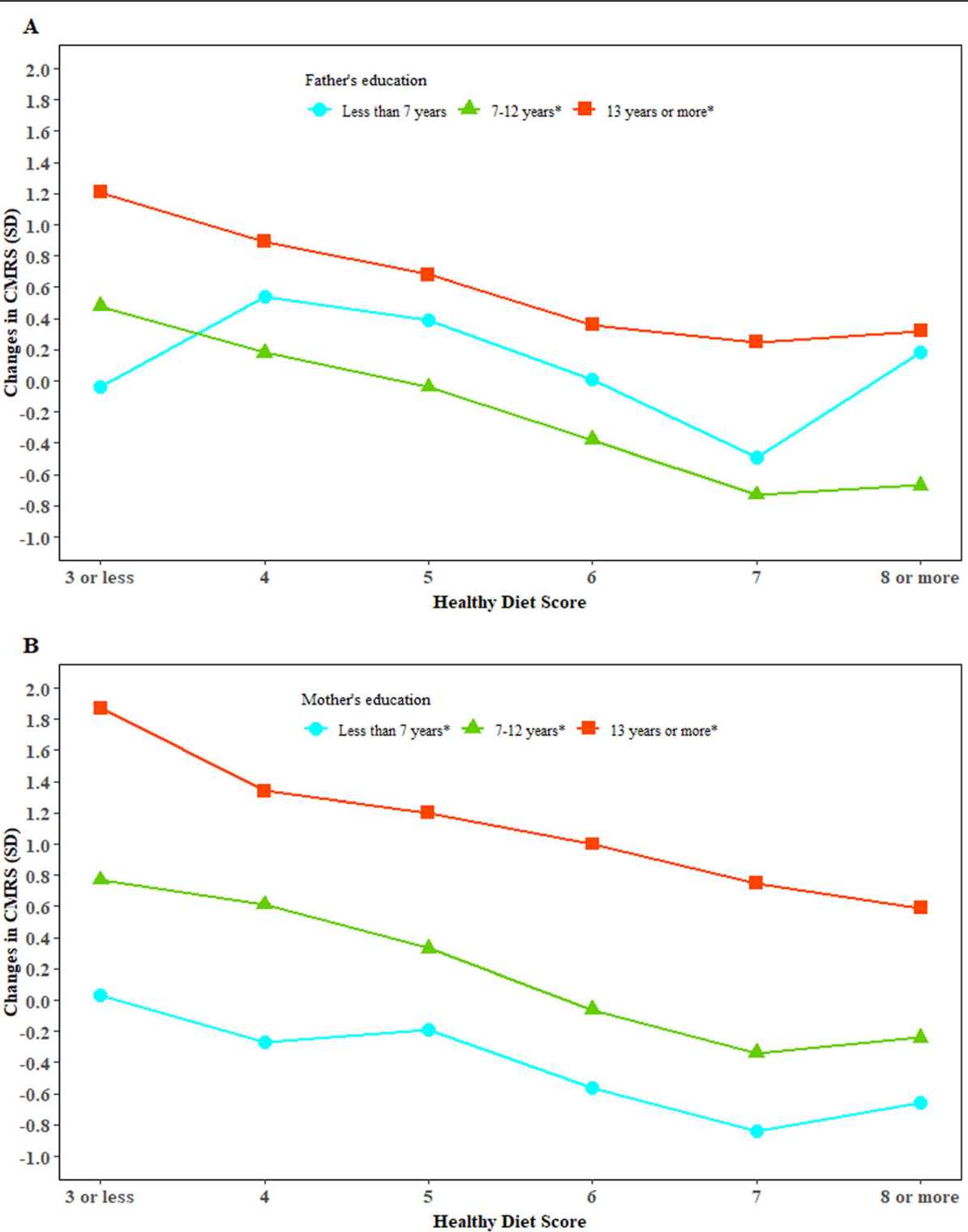

Fig. 3 Associations between healthy diet score and changes in cardiometabolic risk score modified by parental education. CMRS, cardiometabolic risk score; SD, standard deviation. The general linear regression model was used to test the interaction adjusted for classes in schools as random effects and characteristics of the individuals including age, sex, intervention, grade, puberty, BMl, physical activity, CMRS, and intake of energy, fiber, vegetable, fruit, pork, legumes, and nuts at baseline, birth weight, breastfeeding, household income, or parental BMI and education. We examined whether the association between healthy diet score and CMRS was modified by sex, grade, birthweight, household income, parental $\mathrm{BMI}$, and parental education and a significant interaction were observed only for healthy diet score and parental education. * represents there is a significant association between healthy diet score and change in CMRS

given all data were collected in May of the year. Furthermore, our HDS was validated in a Chinese population, but whether HDS was predictive of CMR needs to be examined in other ethnic groups. The validation dataset is also limited by only having several CMR factors measured at baseline and follow-up, which makes it impossible to compute CMRS. Thirdly, several food items such as algae and fungi were not frequently consumed by people in countries other than Asia therefore the HDS was not applied to these populations. However, nuts, milk, and vegetables (11th, 12th, and 13th leading predictors in our study) instead of these food items may be included in the calculation of the HDS. Fourthly, the importance of an individual food for the CMRS is deriving partly from that food but also from other foods it is correlated with, which was not accounted for in our machine learning analysis. Fithly, the follow-up period of our study (one year) is relatively short to judge the effect of dietary factors on change in CMR, therefore longitudinal studies with long-term follow-up are needed to 
warrant our findings. Finally, because of the observational nature of the analysis in the present study, causal relations could not be established based on our findings.

\section{Conclusions}

Diets high in seafood, rice, and red meat other than pork and low in refined grains, fried foods, SSBs, wheat, fungi and algae, roots and tubers are leading healthy diet factors for changes in CMR factors in children. HDS based on these leading dietary determinants is strongly predictive of CMR factors.

\section{Supplementary information}

Supplementary information accompanies this paper at https://doi.org/10. 1186/s12937-020-00611-2.

Additional file 1.

\section{Abbreviations}

BMI: body mass index; CMRS: cardiometabolic risk score; DBP: diastolic blood pressure; HDL-C: high-density lipoprotein cholesterol; HDS: healthy diet score; LDL-C: low-density lipoprotein cholesterol; MAP: mean arterial pressure; SBP: systolic blood pressure; SEM: standard error of the mean; SSBs: sugarsweetened beverages; TC: total cholesterol; TG: triglyceride

\section{Acknowledgments}

The authors would like to acknowledge the support from other team members and the participated students, teachers, parents and local education and health staff members.

\section{Authors' contributions}

Conceptualization, G.M.; Methodology, X.S.; Software, X.S.; Validation, X.S., and Y.L.; Formal Analysis, X.S.; Investigation, H.X., H.X., Q.Z., A.L., S.D., and H.G.; Resources, G.M.; Data Curation, H.X., H.X., Q.Z., A.L., S.D., and H.G.; Writing Original Draft Preparation, X.S.; Writing - Review \& Editing, X.S., Y.L., and G.M.; Visualization, X.S.; Supervision, G.M.; Project Administration, G.M.; Funding Acquisition, G.M. The author(s) read and approved the final manscript.

\section{Funding}

This project was funded by the China Ministry of Science \& Technology as Key Projects in the National Science \& Technology Pillar Program during the Eleventh Five-Year Plan Period (2008BAI58B05).

\section{Availability of data and materials}

The datasets generated and/or analyzed during the current study are not publicly available due to the privacy protection of the participants but are available from the corresponding author on reasonable request.

\section{Ethics approval and consent to participate}

The study protocol was approved by the Ethical Review Committee of the National Institute for Nutrition and Food Safety, Chinese Centre for Disease Control and Prevention. Written informed consent was obtained from the next of kin, carers, or guardians of all the participants.

\section{Consent for publication}

Not applicable.

\section{Competing interests}

The authors declare that they have no competing interests.

\section{Author details}

${ }^{1}$ National Institute for Nutrition and Health, Chinese Center for Disease Control and Prevention, Beijing, China. ${ }^{2}$ School of Behavioural and Health Sciences, Australian Catholic University, Melbourne, Australia. ${ }^{3}$ Department of Medicine (Royal Melbourne Hospital), University of Melbourne, Melbourne, Australia. ${ }^{4}$ Department of Nutrition, Harvard T. H. Chan School of Public
Health, Boston, MA, USA. ${ }^{5}$ Institute of food and nutrition development, Ministry of Agriculture and Rural Affairs, Beijing, China. ${ }^{6}$ Chinese Nutrition Society, Beijing, China. ${ }^{7}$ School of Public Health, Fudan University, Shanghai, China. ${ }^{8}$ Department of Nutrition and Food Hygiene, School of Public Health, Peking University, 38 Xue Yuan Road, Beijing 100191, China.

Received: 24 February 2020 Accepted: 24 August 2020

Published online: 19 September 2020

\section{References}

1. O'Neill S, O'Driscoll L. Metabolic syndrome: a closer look at the growing epidemic and its associated pathologies. Obes Rev. 2015;16(1):1-12. https:// doi.org/10.1111/obr.12229.

2. Grundy SM. Metabolic syndrome pandemic. Arterioscler Thromb Vasc Biol. 2008;28(4):629-36. https://doi.org/10.1161/atvbaha.107.151092.

3. Adair LS, Gordon-Larsen P, Du SF, Zhang B, Popkin BM. The emergence of cardiometabolic disease risk in Chinese children and adults: consequences of changes in diet, physical activity and obesity. Obes Rev. 2014;15(Suppl 1): 49-59. https://doi.org/10.1111/obr.12123.

4. Laitinen TT, Pahkala K, Magnussen CG, Viikari JS, Oikonen M, Taittonen L, Mikkila V, Jokinen E, Hutri-Kahonen N, Laitinen T, Kahonen M, Lehtimaki T, Raitakari OT, Juonala M. Ideal cardiovascular health in childhood and cardiometabolic outcomes in adulthood: the Cardiovascular Risk in Young Finns Study. Circulation. 2012;125(16):1971-8. https://doi.org/10.1161/ circulationaha.111.073585.

5. Bao W, Srinivasan SR, Wattigney WA, Berenson GS. Persistence of multiple cardiovascular risk clustering related to syndrome $X$ from childhood to young adulthood. The Bogalusa Heart Study. Arch Intern Med. 1994;154(16): 1842-7.

6. Berenson GS (2002) Childhood risk factors predict adult risk associated with subclinical cardiovascular disease. The Bogalusa Heart Study. Am J Cardiol 90 (10c):3l-7l.

7. Reilly JJ, Kelly J. Long-term impact of overweight and obesity in childhood and adolescence on morbidity and premature mortality in adulthood: systematic review. Int J Obes. 2011;35(7):891-8. https://doi.org/10.1038/ijo. 2010.222.

8. Park MH, Falconer C, Viner RM, Kinra S. The impact of childhood obesity on morbidity and mortality in adulthood: a systematic review. Obes Rev. 2012; 13(11):985-1000. https://doi.org/10.1111/j.1467-789X.2012.01015.X.

9. Ng M, Fleming T, Robinson M, Thomson B, Graetz N, Margono C, Mullany EC, Biryukov S, Abbafati C, Abera SF, Abraham JP, Abu-Rmeileh NM, Achoki T, AlBuhairan FS, Alemu ZA, Alfonso R, Ali MK, Ali R, Guzman NA, Ammar W, Anwari P, Banerjee A, Barquera S, Basu S, Bennett DA, Bhutta Z, Blore J, Cabral N, Nonato IC, Chang JC, Chowdhury R, Courville KJ, Criqui MH, Cundiff DK, Dabhadkar KC, Dandona L, Davis A, Dayama A, Dharmaratne SD, Ding EL, Durrani AM, Esteghamati A, Farzadfar F, Fay DF, Feigin VL, Flaxman A, Forouzanfar MH, Goto A, Green MA, Gupta R, Hafezi-Nejad N, Hankey GJ, Harewood HC, Havmoeller R, Hay S, Hernandez L, Husseini A, Idrisov BT, Ikeda $N$, Islami $F$, Jahangir $E$, Jassal SK, Jee SH, Jeffreys M, Jonas JB, Kabagambe EK, Khalifa SE, Kengne AP, Khader YS, Khang YH, Kim D, Kimokoti RW, Kinge JM, Kokubo Y, Kosen S, Kwan G, Lai T, Leinsalu M, Li Y, Liang X, Liu S, Logroscino G, Lotufo PA, Lu Y, Ma J, Mainoo NK, Mensah GA, Merriman TR, Mokdad AH, Moschandreas J, Naghavi M, Naheed A, Nand D, Narayan KM, Nelson EL, Neuhouser ML, Nisar MI, Ohkubo T, Oti SO, Pedroza A, Prabhakaran D, Roy N, Sampson U, Seo H, Sepanlou SG, Shibuya K, Shiri R, Shiue I, Singh GM, Singh JA, Skirbekk V, Stapelberg NJ, Sturua L, Sykes BL, Tobias M, Tran BX, Trasande L, Toyoshima H, van de Vijver S, Vasankari TJ, Veerman JL, Velasquez-Melendez G, Vlassov W, Vollset SE, Vos T, Wang C, Wang X, Weiderpass E, Werdecker A, Wright JL, Yang YC, Yatsuya H, Yoon J, Yoon SJ, Zhao Y, Zhou M, Zhu S, Lopez AD, Murray CJ, Gakidou E. Global, regional, and national prevalence of overweight and obesity in children and adults during 1980-2013: a systematic analysis for the Global Burden of Disease Study 2013. Lancet. 2014;384(9945):766-81. https://doi.org/10.1016/ s0140-6736(14)60460-8.

10. DeBoer MD. Assessing and Managing the Metabolic Syndrome in Children and Adolescents. Nutrients. 2019;11(8). https://doi.org/10.3390/nu11081788.

11. Verduci E, Lassandro C, Giacchero R, Miniello VL, Banderali G, Radaelli G. Change in Metabolic Profile after 1-Year Nutritional-Behavioral Intervention in Obese Children. Nutrients. 2015;7(12):10089-99. https://doi.org/10.3390/ nu7125520. 
12. Forouhi NG, Misra A, Mohan V, Taylor R, Yancy W. Dietary and nutritional approaches for prevention and management of type 2 diabetes. BMJ. 2018; 361:k2234. https://doi.org/10.1136/bmj.k2234.

13. Mozaffarian D. Dietary and Policy Priorities for Cardiovascular Disease, Diabetes, and Obesity: A Comprehensive Review. Circulation. 2016;133(2): 187-225. https://doi.org/10.1161/circulationaha.115.018585.

14. Hilger-Kolb J, Bosle C, Motoc I, Hoffmann K. Associations between dietary factors and obesity-related biomarkers in healthy children and adolescents a systematic review. Nutr J. 2017;16(1):85. https://doi.org/10.1186/s12937017-0300-3.

15. Shang X, Li Y, Liu A, Zhang Q, Hu X, Du S, Ma J, Xu G, Li Y, Guo H, Du L, Ma $G$. Dietary pattern and its association with the prevalence of obesity and related cardiometabolic risk factors among Chinese children. PLoS One. 2012;7(8):e43183. https://doi.org/10.1371/journal.pone.0043183.

16. Kelishadi R, Heshmat R, Mansourian M, Motlagh ME, Ziaodini H, Taheri M, Ahadi Z, Aminaee T, Goodarzi A, Mansourian M, Qorbani M, Mozafarian N. Association of dietary patterns with continuous metabolic syndrome in children and adolescents; a nationwide propensity score-matched analysis: the CASPIAN-V study. Diabetol Metab Syndr. 2018;10:52. https://doi.org/10. 1186/s13098-018-0352-3.

17. Pinto A, Santos AC, Lopes C, Oliveira A. Dietary patterns at 7 year-old and their association with cardiometabolic health at 10 year-old. Clin Nutr. 2019. https://doi.org/10.1016/j.clnu.2019.05.007.

18. Lazarou C, Newby PK. Use of dietary indexes among children in developed countries. Adv Nutr. 2011;2(4):295-303. https://doi.org/10.3945/an.110. 000166.

19. Trijsburg L, Talsma EF, de Vries JHM, Kennedy G, Kuijsten A, Brouwer ID. Diet quality indices for research in low- and middle-income countries: a systematic review. Nutr Rev. 2019. https://doi.org/10.1093/nutrit/nuz017.

20. Li Y, Hu X, Zhang Q, Liu A, Fang H, Hao L, Duan Y, Xu H, Shang X, Ma J, Xu G, Du L, Li Y, Guo H, Li T, Ma G. The nutrition-based comprehensive intervention study on childhood obesity in China (NISCOC): a randomised cluster controlled trial. BMC Public Health. 2010;10:229. https://doi.org/10. 1186/1471-2458-10-229.

21. Yang Y, Wang G, Pan X. China Food Composition. Beijing: Peking Medical University; 2009

22. Liu AL, Ma GS, Zhang Q, Ma WJ. Reliability and validity of a 7-day physical activity questionnaire for elementary students. Zhonghua liu xing bing xue za zhi = Zhonghua liuxingbingxue zazhi. 2003;24(10):901-4.

23. Deurenberg P, van der Kooy K, Leenen R, Weststrate JA, Seidell JC. Sex and age specific prediction formulas for estimating body composition from bioelectrical impedance: a cross-validation study. Int J Obes. 1991;15(1):17-25.

24. Eisenmann JC. On the use of a continuous metabolic syndrome score in pediatric research. Cardiovasc Diabetol. 2008;7:17. https://doi.org/10.1186/ 1475-2840-7-17.

25. Breiman L. Random forests. Mach Learn. 2001;45(1):5-32.

26. Y. Freund, R. E Schapire (1997) A Decision-Theoretic Generalization of On-Line Learning and an Application to Boosting. J Comput Syst Sci 55 (1):119-139.

27. Benjamini Y, Hochberg Y. Controlling the false discovery rate: A practical and powerful approach to multiple testing. J R Stat Soc Ser. 1995;57:289-300.

28. Cohen J (1988) Statistical Power Analysis for the Behavioral Sciences. Hillsdale, N.J. : L. Erlbaum Associates,.

29. Mager DR, Iniguez IR, Gilmour S, Yap J. The effect of a low fructose and low glycemic index/load (FRAGILE) dietary intervention on indices of liver function, cardiometabolic risk factors, and body composition in children and adolescents with nonalcoholic fatty liver disease (NAFLD). JPEN J Parenter Enteral Nutr. 2015;39(1):73-84. https://doi.org/10.1177/ 0148607113501201.

30. Eloranta AM, Lindi V, Schwab U, Kiiskinen S, Venalainen T, Lakka HM, Laaksonen DE, Lakka TA. Dietary factors associated with metabolic risk score in Finnish children aged 6-8 years: the PANIC study. Eur J Nutr. 2014;53(6): 1431-9. https://doi.org/10.1007/s00394-013-0646-z.

31. Meng H, Matthan NR, Fried SK, Berciano S, Walker ME, Galluccio JM, Lichtenstein AH. Effect of Dietary Carbohydrate Type on Serum Cardiometabolic Risk Indicators and Adipose Tissue Inflammatory Markers. J Clin Endocrinol Metab. 2018;103(9):3430-8. https://doi.org/10. 1210/jc.2018-00667.

32. Fillion L, Henry CJ. Nutrient losses and gains during frying: a review. Int J Food Sci Nutr. 1998;49(2):157-68.

33. Pokorn J, Panek J, Trojakova L. Effect of food component changes during frying on the nutrition value of fried food. Forum Nutr. 2003;56:348-50.
34. Cahill LE, Pan A, Chiuve SE, Sun Q, Willett WC, Hu FB, Rimm EB. Fried-food consumption and risk of type 2 diabetes and coronary artery disease: a prospective study in 2 cohorts of US women and men. Am J Clin Nutr. 2014;100(2):667-75. https://doi.org/10.3945/ajcn.114.084129.

35. Guallar-Castillon P, Rodriguez-Artalejo F, Fornes NS, Banegas JR, Etxezarreta PA, Ardanaz E, Barricarte A, Chirlaque MD, Iraeta MD, Larranaga NL, Losada A, Mendez M, Martinez C, Quiros JR, Navarro C, Jakszyn P, Sanchez MJ, Tormo MJ, Gonzalez CA. Intake of fried foods is associated with obesity in the cohort of Spanish adults from the European Prospective Investigation into Cancer and Nutrition. Am J Clin Nutr. 2007;86(1):198-205. https://doi. org/10.1093/ajcn/86.1.198.

36. Binnie MA, Barlow $K$, Johnson V, Harrison C. Red meats: time for a paradigm shift in dietary advice. Meat Sci. 2014;98(3):445-51. https://doi.org/10.1016/j. meatsci.2014.06.024.

37. Lee DH, Yang M, Giovannucci EL, Sun Q, Chavarro JE. Mushroom consumption, biomarkers, and risk of cardiovascular disease and type 2 diabetes: a prospective cohort study of US women and men. Am J Clin Nutr. 2019. https://doi.org/10.1093/ajcn/nqz057.

38. Dragsted LO. Mushrooms and health. Am J Clin Nutr. 2019. https://doi.org/ 10.1093/ajcn/nqz096.

39. Wells ML, Potin P, Craigie JS, Raven JA, Merchant SS, Helliwell KE, Smith AG, Camire ME, Brawley SH. Algae as nutritional and functional food sources: revisiting our understanding. J Appl Phycol. 2017;29(2):949-82. https://doi. org/10.1007/s10811-016-0974-5.

40. Pala V, Lissner L, Hebestreit A, Lanfer A, Sieri S, Siani A, Huybrechts I, Kambek L, Molnar D, Tornaritis M, Moreno L, Ahrens W, Krogh V. Dietary patterns and longitudinal change in body mass in European children: a follow-up study on the IDEFICS multicenter cohort. Eur J Clin Nutr. 2013; 67(10):1042-9. https://doi.org/10.1038/ejcn.2013.145.

41. Asghari G, Yuzbashian E, Mirmiran P, Hooshmand F, Najafi R, Azizi F. Dietary Approaches to Stop Hypertension (DASH) Dietary Pattern Is Associated with Reduced Incidence of Metabolic Syndrome in Children and Adolescents. J Pediatr 174:178-184.e171. 2016. https://doi.org/10.1016/j.jpeds.2016.03.077.

42. Velazquez-Lopez L, Santiago-Diaz G, Nava-Hernandez J, Munoz-Torres AV, Medina-Bravo P, Torres-Tamayo M. Mediterranean-style diet reduces metabolic syndrome components in obese children and adolescents with obesity. BMC Pediatr. 2014:14:175. https://doi.org/10.1186/1471-2431-14-175.

43. laccarino Idelson P, Scalfi L, Valerio G. Adherence to the Mediterranean Diet in children and adolescents: A systematic review. Nutr Metab Cardiovasc Dis. 2017;27(4):283-99. https://doi.org/10.1016/j.numecd.2017.01.002.

\section{Publisher's Note}

Springer Nature remains neutral with regard to jurisdictional claims in published maps and institutional affiliations.
Ready to submit your research? Choose BMC and benefit from:
- fast, convenient online submission
- thorough peer review by experienced researchers in your field
- rapid publication on acceptance
- support for research data, including large and complex data types
- gold Open Access which fosters wider collaboration and increased citations
- maximum visibility for your research: over $100 \mathrm{M}$ website views per year
At BMC, research is always in progress.
Learn more biomedcentral.com/submissions 